The Great Arizona

Orphan Abduction 



\title{
The Great Arizona Orphan Abduction
}

\author{
兽 \\ LINDA GORDON
}

HARVARD UNIVERSITY PRESS

Cambridge, Massachusetts 
Copyright (C) 1999 by Linda Gordon

All rights reserved

Printed in the United States of America

Fifth printing, 2001

First Harvard University Press paperback edition, 2001

Library of Congress Cataloging-in-Publication Data

Gordon, Linda.

The great Arizona orphan abduction / Linda Gordon.

p. $\mathrm{cm}$.

Includes bibliographical references and index.

ISBN 0-674-36041-9 (cloth : alk. paper)

ISBN 0-674-00535-X (pbk.)

1. Clifton (Ariz.)-Race relations. 2. Orphans-Arizona-

Clifton-History-20th century. 3. Kidnapping-ArizonaClifton-History-20th century. 4. Catholic ChurchArizona-Clifton-History-20th century. 5. Mexican Americans-Arizona-Clifton-History-20th century.

6. Whites-Arizona-Clifton-History-20th century.

7. Vigilantes-Arizona-Clifton-History-20th century.

I. Title.

F819.C55G67 1999

305.8'009791'51-dc21

99-30984 
To see a World in a grain of sand ...

-William Blake,

"Auguries of Innocence" 
